GU J Sci, Part C, 6(2): 345-357 (2018)

Gazi Üniversitesi
Fen Bilimleri Dergisi
PART C: TASARIM VE TEKNOLOJI
dergipark.gov.tr/http-gujsc-gazi-edu-tr

\title{
Müșteri Korelasyonuna Göre Hafif Bir Ticari Otonun Yorulma Test Parkurunun Oluşturulması
}

\author{
Arif Şenol ŞENER ${ }^{1, *}$ \\ ${ }^{I}$ Istanbul Gelişim Üniversitesi, Mühendislik ve Mimarlık Fakültesi, Mekatronik Bölümü, 34310, Avcılar/ISTANBUL
}

\begin{abstract}
$\ddot{O} \mathbf{z}$
Makale Bilgisi

Bașvuru: 21/11/2017

Düzeltme: $18 / 01 / 2018$

Kabul: $30 / 01 / 2018$

Anahtar Kelimeler

Otomobil kullanımı

Test parkuru

Yorulma analizi

Çevrim sayma

Ağırlıkl ortalama indeksi

Keywords

Ürün tasarım sürecinde en kritik olan ve zor tespit edilen parametrelerden olan bir parçanın yorulma ömrü, üretici firmalar tarafından hızlandırıcı testlerle doğrulanmaktadır. Bunun için üreticiler yorulma etkisi matematiksel olarak tespit edilmiş özel test parkuruna ve/veya güzergahlarına ihtiyaç duyarlar. Bu çalışmada, hızlandırılmış bir test parkurunu oluşturmak için ilk olarak Türk müşterilerinin otomobil kullanımları anket yöntemi ile tespit edilmiştir. Yol testleri, Türkiye'de 50 şehri içerecek şekilde belirlenmiş bir yol haritasında, sensörlerle donatılmış bir araç ile gerçekleştirilmiştir. Ham veriler üzerinde veri işleme ve detaylandırma yapılmıştır. Yaprak yay, tahrik mili, direksiyon rod kolu gibi gerilme meydana gelen parçalardan elde edilen sinyallerin değerlendirilmesinde 3 eksenli Rainflow metodu kullanılmıştır. Buna karşın vites değiştirme oranı, fren adedi miktarı vb. gibi üzerinde gerilme oluşmayan parçalar için 2 eksenli Level-Crossing metodu tercih edilmiştir. Türk müşteri profili sinyaller işlendikten sonra anketlerden elde edilen Türk müşteri otomotiv kullanım yüzdeleriyle çarpılarak her sensör için hesaplanmış ve bu şekilde genel olarak Türk müşteri profili oluşturulmuştur. Yorulma ömrü etkileri ağırlıklı ortalama yöntemi kullanılarak hesaplanıp, Türk müşteri profilinin yorulma etkisine karşılık gelecek şekilde üretici firma yakınlarında hızlandırılmış bir test parkuru oluşturulmuştur. Bir Avrupa ülkesinde üretilen binek otomobillerin araç kullanım sonuçları ve Türkiye'de üretilen hafif ticari oto müşteri kullanım sonuçları karşılaştırılmıştır.
\end{abstract}

Automotive usage

Test track

Fatigue life analysis

Cycle counting

Weighted average index

\section{Formation of a Fatigue Test Track for a Light Commercial Vehicle According to Customer Correlation}

\begin{abstract}
Fatigue life, one of the most critical and difficult parameters of the product design process, is verified by accelerated test by the manufacturers. For this reason, the manufacturers need specific test tracks and / or routes that are mathematically tested for fatigue effect. In this study, firstly the automotive usage of Turkish customers was determined by means of questionnaires in order to create an accelerated test track. Road tests were executed with a vehicle equipped with sensors on determined road map including 50 routes in Turkey. Data elaboration and detailing were executed on the raw data. For the stressed components such as leaf spring, driving shaft, steering wheel tie rod, Rain-flow cycle counting method was used. Despite that 2 axes Level-Crossing method was preferred for the non stressed components such as gear change ratio, breaking quantity etc. Data of mission profile belong to each sensor were handled by multiplying elaborated signals with Turkish customer automotive usage. The fatigue life effects were calculated using the weighted average method and an accelerated test track was created near the manufacturer corresponding to the fatigue effect of the Turkish mission profile. The usage results of passenger cars produced in an European country and costumer usage results of the light commercial vechile produced in Turkey were compared.
\end{abstract}

\section{GİRIŞ (INTRODUCTION)}

Günümüzde, otomobil müşterileri otomobillerinde yüksek performans, düşük yakıt tüketimi, konfor, yüksek güvenilirlik ve dayanıklılık içeren kaliteli araçlar beklemektedir. Kalite kavramının parametrelerinden biri olan dayanıklılık, uzun km kullanımında ortaya çıkar. Bu nedenle, bir otomobilin 
dayanıklık testi sonuçlarının müşteri kullanımına bağlı olarak elde edilmesi uzun süreç gerektirmektedir [1]. Bir aracın servis ömrü, güvenilirlik ve emniyet süreçlerinin belirlenmesi, araç yapılarının tasarım süreci için hayati önem taşımaktadır [2,3]. Araç mühendisliğinin amacı, bir taraftan çok kısa olan bu geliştirme döngüsünde güvenlik ve güvenilirlik gibi iki özelliği düşünürken, diğer taraftan düşük maliyetli ve hafif tasarımı bir araya getirip diğer firmalarla rekabet etmektir. Otomobil firmaları özellikle fonksiyonel testlerden biri olan dayanıklılık testini, öngörülen metodlarla kısa zaman aralığında yaparak o projedeki hata sıklık miktarını ve proje maliyetini düşürerek müşterilerinin tüm beklentilerini garanti altına almak zorundadır [4]. Bir parçanın dayanıklılığını etkileyen başlıca parametreler malzeme, geometri ve yük spektrumunun bir fonksiyonu olan taşıtın çalıştığı pazardaki müşteri kullanımıdır $[5,6]$.

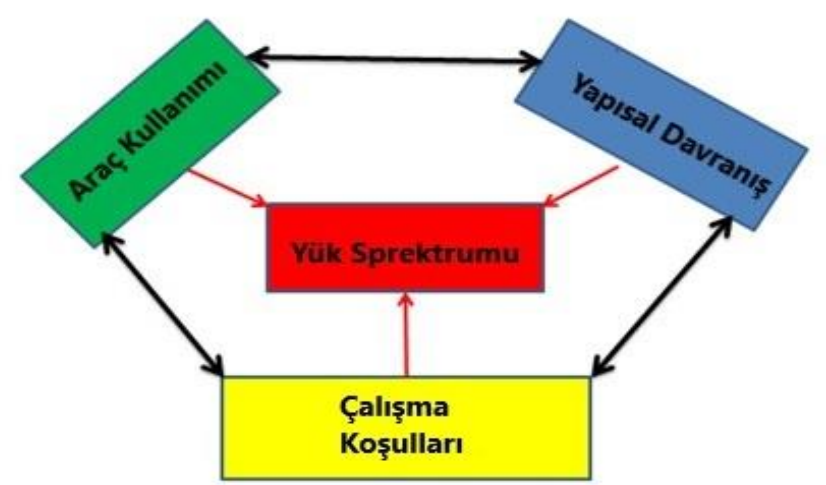

Şekil 1. Yük spektrumu parametreleri [5]

Şekil l'de Yük spektrumunun parametreleri gösterilmiştir [5, 6]. Çalışmadaki yük koşulları, bir ürünün ve bileşenlerinin servis ömrü için büyük önem taşımaktadır [5]. Bir araç ve parçalarının ömrü tahminini ve hasar görmemiş zamanı etkileyen yük spektrumu aracın satıldığı pazardaki güvenirlirilik gereksinimlerini de hesaba katan müşteri profilini referans alan yol testleri ve bilgisayar sanal analizleri ile hesaplanarak belirlenmelidir [6]. Genel olarak, otomotiv üreticileri tarafından kullanılan dört dayanıklılık testi yöntemi vardır. Bunlar; Sonlu Elemanlar Analizi (SEA), Tek parça yorulma testleri, Araç/Grup komponent testleri ve hızlandırılmış test parkurları (HTP) testleridir. Yorulma analizi SEA kullanılarak kısa sürede uygun bir tasarım çözümü sağlanabilir ve gerekli çözümler başarılabilir [7, 8]. Bir ürünün karmaşıklığı, otomobil şirketleri arasındaki rekabet ve müşterilerin beklentileri otomobil şirketlerini üretecekleri otomobillerin prototiplerini halka açık yollarda ve özel test parkurlarında ve ürünün satılacağı pazardaki tüm çevre faktörlerini içine alan bir dizi test yaparak güvenilirliğini kanıtlamaya zorlamaktadır $[2,9,10]$. Dört metodun her birinin hem avantaj ve hem de dezavantajları vardır [11,12]. Butün bu çalışmalar içinde pahalı olmasına rağmen en iyi müşteri profilini yansıtan yöntem ise HTP 'da yapılan testlerdir [11-13]. Bu nedenle, günümüzde otomobil şirketleri, projedeki garanti maliyetleri açısından müşteri beklentilerini belirleyen tasarım ve doğrulama sürecinde otomobil parçalarının dayanıklılığını doğrulamak için bir veya birkaç yöntem kullanmaktadır [14].

Dayanıklılık testinin tarihçesine bakıldığında, dayanıklılık test çalışmaları tahminlerden yola çıkarak, en kötü durumu simule etme, pratik tecrübelerden, temel yol- yük verilerinden, yasal şartnameleri yerine getirme olarak tasarlanmış ve gerçekleştirilmiştir. Bir önceki paragrafta açıklanan bütün bu testler, aracın bütün yorulma hayatını içermesinden ötürü çok ağır bir şekilde dayanım testi yapılmasına yöneltir. $\mathrm{Bu}$ testler, aracın azami yükte genel mühendislik şartnamesine uyup uymadığından emin olmak için tasarlanmıştır. En önemli ve en zor çalışma, temsili yük spektrumunun nasıl belirleneceğidir. Çünkü şimdiye kadar kullanılan yöntemlerin hepsi ya çok yetersiz kalmakta ya da çok ağır olduğu görülmektedir [14]. Son zamanlarda, araçların ömrü boyunca karşılaşacağı toplam yük spektrumunu belirlemek için yaygın olarak kullanılan yöntemler müşteri kullanım metodlarıdır [14-18]. Müşteri profilini oluşturma çalışmalarından birini EicherTractors Mühendislik Merkezi (ETEC) ve ARAL Tasarım, Hindistan'da traktörlerin tarımda kuru ve ıslak zeminlerinde kullanımının yanısıra tarım dışı traktörlerin kullanımı ve traktörlerin hindistan bölgeleri arasında kullanım farklılıklarını inceleyen müşteri kullanımını temel alarak gerçekleştirmiştir [14-19]. 
Başka bir çalışma ise Brezilya ve İtalya pazarı için FIAT şirketi tarafından yapılmıştır. Günümüzde Brezilya ve Türkiye'de, yeni araç modellerinin geliştirilmesi için kullanılan standart bir yorulma test pisti mevcut değildir. FIAT şirketi frekans bazlı yorulma ömrünü temel alan müşteri kullanımını da hesaba katan Brezilya yolları ile İtalyan yolları ve ayrıca özel test parkuru etkilerini esas alarak araçların yorulma testleri ve temsili yük profilini çıkarma çalışmaları yaparak karşılaştırmalar gerçekleştirilmiştir [20].

FIAT şirketi Ritmo 60 ve Tipo1372 için bir metoduyla diğer bir müşteri kullanımı araştırmasını kara kutu (Black Box) metoduyla gerçekleştirmiş̧tir [17]. Bir başka araştırmada ise FIAT şirketi, cihazlarla donatılmış bir B segment (Punto) aracıyla bir Türk müşteri profilini belirlemek için 1997'de veri toplayarak müşetri profili oluşturmuştur[16].

$\mathrm{Bu}$ çalışmanın diğer çalışmalara kıyasla birinci önemli farkı, tatil konseptinin FIAT İtalyan müşterisi konseptinden ayrışarak bir anket vasıtasıyla Türk müşterisi için yeniden tespit edilmesidir. Çalışmalardan ikinci önemli fark1, Türkiye'de standart bir test pisti olmadığından, MP test parkuru içine normal trafik yollarının yanısıra, çoğunlukla çukurlar, keskin virajlar ve bozuk yol profilleri gibi çok ağır köy yolları belirlenerek, bir miktar da trafik yollarına karıştırılıp yolların yorulma etkileri artırılmıştır [15,20]. Üçüncü önemli fark ise, genellikle otomobil üretici firmaları yol pürüzlülügünü ve yorulma verilerini çoğunlukla yollarda $20 \mathrm{~km}$ lik yorulma karakteristiği çok ağır olan yolun belirli bir kısmında ölçümler alarak yapmalarıdır. Yani, yol yorulma özelliğine ilişkin karakteristik veriler bir şehirden diğer bir şehire tamamen ölçülmemiştir. Bu çalışmada ise ölçümler şehirden şehire ölçümler yapılarak Türkiye'de 50 yolda yaklaşık 45 gigabyte yorulma ham verisi elde edilmiş ve bu ham veriler işledikten sonra, toplam veri dosyası boyutu 45 gigabayttan yaklaşık olarak 200 gigabayta genişletilmiştir[15].

$\mathrm{Bu}$ makalede, otomobillerin araştırma ve geliştirme sürecinde gerekli olan MP ve HTP yapısını oluşturmada bir HTA için ağırlı ortalama metoduna göre nasıl tasarlanabileceği ve uygulanabileceği yöntem, süreçler ve ilgili sonuçlar verilmiştir.

\section{METOD (METHOD)}

Bir araç ya da parçanın hızlandırılmış yorulma testi için, taşıtın normal kullanım şartlarında karşılaştığı bütün yük değerlerine karşılık gelen temsili bir yük spektrumu kullanılmalıdır [5]. Bir parçanın kullanım ömrü genellikle kullanım sırasında yükleme koşullarından etkilenir [5]. Tasarım-proses doğrulama ve güvenilirlik testi için temsili bir yük spektrumu oluşturulması gerkemektedir [5]. Son zamanlarda, bir aracın müşteri kullanımını belirlemek için müşteri kullanımını esas alan anket ve kara kutu adında iki yöntem kullanılmaktadır [14, 15, 17].

\subsection{Kara Kutu Metodu}

$\mathrm{Bu}$ yöntem, gönüllü sürücülerin araçlarının veri toplama cihazları ve sensörleriyle donatılarak uzun bir süre seyahat esnasında verilerinin kaydedilmesi esasına dayanmaktadır. Kaydedilen veriler düzenli olarak peryodik bir şekilde araç üreticisi tarafından sabit bir diske kaydedilerek boşaltılır. Bu metodla veri toplama yaklaşık üç yıl zaman almaktadır. Tüm ölçümlerden sonra veriler istatistiksel olarak değerlendirilerek araç kullanım özellikleri sayısal olarak raporlandırılır [17,18].

\subsection{Anket Metodu}

Anket metodu, araç kullanımı vb. bilgileri toplamak için aynı segment araçların müşterilerine telefonla anket yapılarak araç kullanım bilgileri ve benzeri diğer bilgileri elde etmeyi esas almaktadır $[5,14,19]$. Anket ölçüm sonuçlarının değerlendirilmesi sonucunda, cihaz ve sensörlerle donanımlı bir araç ve/veya birkaç araç ile bir yol testi simülasyonu yapılır. Yol testi sırasında veriler, değişik manevraların yapıldığı ve değişik yol profillerinde (şehiriçi, şehirlerarası, dağlık alanlar, kırsal alanlar vb.) ve otomobil yük şartlarında bir test şoförü veya farklı şoförler kullanılarak toplanır $[14,17]$. Toplanan ham sinyaller yol sınıflarına ve yük koşullarına göre sınıflandırıldıktan sonra veri işleme yapılır.Veri işlemesi bitmiş sinyaller 2 yada 3-boyutlu matris aralıklarında istatistiksel sinyal sayma metodlarıyla işlemden geçirilir.

Müşteri kullanımı, araç yükü ve yol tipi ile düzenlenerek her bir sensor için $200.000 \mathrm{~km}$ lik bir MP oluşturuurr. Metodoloji; eğer aynı girdiler tekrarlanabilirse, aynı hasarın oluşacağına dayanır. [14]. MP 
bulunması nın ardından aynı yorulma etkisini yaratacak hızlandırılmış test parkuru veya test bankosunda yapılacak tesler için yeni yol sinyalleri oluşturulur. Eğer aynı girişler sağlanırsa, çeşitli formların matris hesabı, yol uyarma sinyallerinin karışımının değerlendirilmesi için bir model sağlayacak ve test uzunluğunu veya test süresini optimize edecektir.

$$
\mathrm{P}[\mathrm{Y} 1]+\mathrm{R}[\mathrm{Y} 2]+\mathrm{S}[\mathrm{Y} 3]+\ldots \ldots \ldots \ldots \ldots . . .+\mathrm{Z}[\mathrm{Yn}]=[\mathrm{H}]
$$

Burada P, R, S, .. Z, test verilerinin çarpanlarıdır. [Y1], [Y2], ... [Yn] test ölçümlerinin matrisleridir ve $[\mathrm{H}]$ müşteri hedef ölçümlerinin toplam matrisidir. Bu şekilde $\mathrm{Y} 1$ yolunun zamanı, Y2 yolu zamanı, H hasar etkisini verene kadar devam edecek kadar açıktır [14].

\section{UYGULAMA (APPLICATION)}

\subsection{Türk Müşteri Profilinin Tanımlanması-Anket Uygulaması}

Diğer yöntemlerle karşılaştırıldığında düşük maliyetli, hızlı veri toplanabilmesi ve veri değerlendirme esnekliği sağalamasından dolayı bu çalışmada "Anket' metodu seçilmiştir. Bir HTA'in Türkiye'deki müşteri kullanımı profili, üretici firma bayilerinin desteğiyle Türk müşterilerine yüz yüze uygulanan bir anket ile geliştirilmiştir.

\subsection{Türk Müşteri Profilinin Tanımlanması -Yol Test Haritasının Belirlenmesi}

Şekil 2'de verilen renkli test güzergahı, bölgelere göre HTA'ın bögesel satış yüzdeleri, önceki model deneyimleri, iklim koşulları ve Türkiye coğrafyası referans alınarak oluşturulmuştur. Bu haritadaki yollar dört grupta sınıflandırılmıştır; şehir içi kullanımı için İstanbul ve Bursa'da, dağlık yollar için genelde Karadeniz bölgesinde, sıcak iklim ve kavisli yol koşulları içeren şehirlerarası yollar için Akdeniz'de, Orta Anadolu'daki yollar ise yüksek irtifalar, sıcaklıklar ve kentler arasındaki uzak mesafeler ile karakterize edilmiştir. Otoyol karaketristiği için ise İstanbul-Ankara ve Adana-Gaziantep otoyolu belirlenmiş güzergahta veri toplama işlemleri için tasarlanarak şekil 2 deki test güzergahı, yollardan veri toplamak için oluşturulmuştur $[10,11]$.

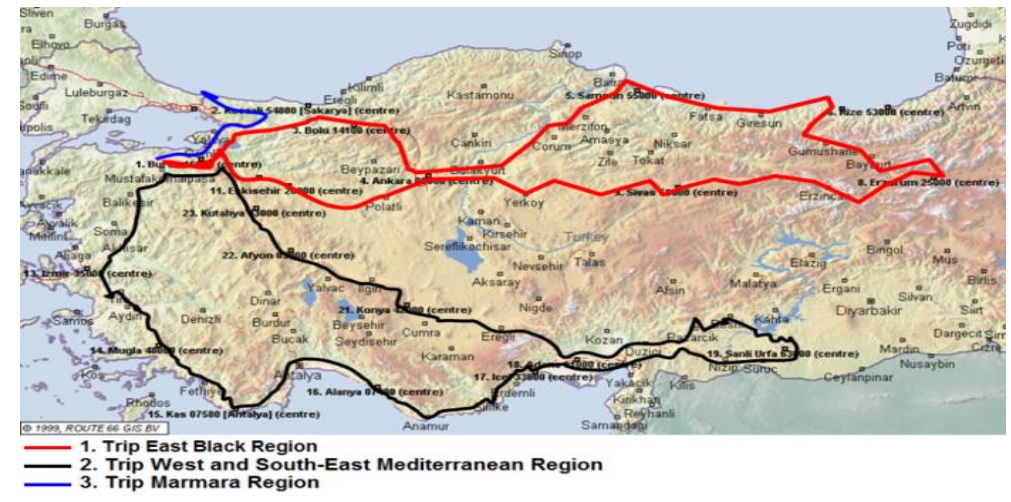

Şekil 2. Yol test haritas1 [15]

\subsection{Türk Müşteri Profilinin Tanımlanması -MP Saptamak İçin Veri Toplama}

Veri ölçümleri sensörlerle donatılmış bir araçla normal sürücülerin otomobillerini kullandıkları yollarda uzman bir test şoförü ve bir mühendis tarafından tam yükte genelde sürücüleri takip ederek şekil 2' de gösterilen güzergahda gerçekleştirilmiştir. 


\subsection{Veri İşleme}

Yorulma dış yükleri, doğrudan zamana bağlı olarak ölçülmez. Bunun yerine, aracın bazı parçalarında sensörlerle dış yüklerin reaksiyonları ölçülür [5]. Spike (sıçramış sinyal) analizi, frekans analizi, filtreleme, aritmetik işlemler ve istatistiksel sayım işlemi gibi işlemler ham veriler üzerinde yapılmıştır [7, 21].

Spike Analizi: Veri toplama sırasında, çevresel ve fiziksel faktörlerden dolayı ortaya çıkan bazı spike lar görsel ve istatistiksel yöntemlerle ortadan kaldırılmıştır [7, 21].

Filtreleme: Yorulma analizleri için aracın süspansiyon parçalarının frekans aralığı $40 \mathrm{~Hz}$ ve $60 \mathrm{~Hz}$ arasındadır. Yol simülasyonu için genellikle $100 \mathrm{~Hz}$ üzerindeki uyarımın ihmal edilebileceği kabul edilmektedir [7, 15, 16, 21]. Şekil 3'de, $100 \mathrm{~Hz}$ üzerindeki frekansı yüksek düşük genlikli sinyaller, yorulma analizleri için anlamlı değildir ve bir alçak geçiren filtre ile orijinal veriden çıkarılmıştır [15, $16,21]$.

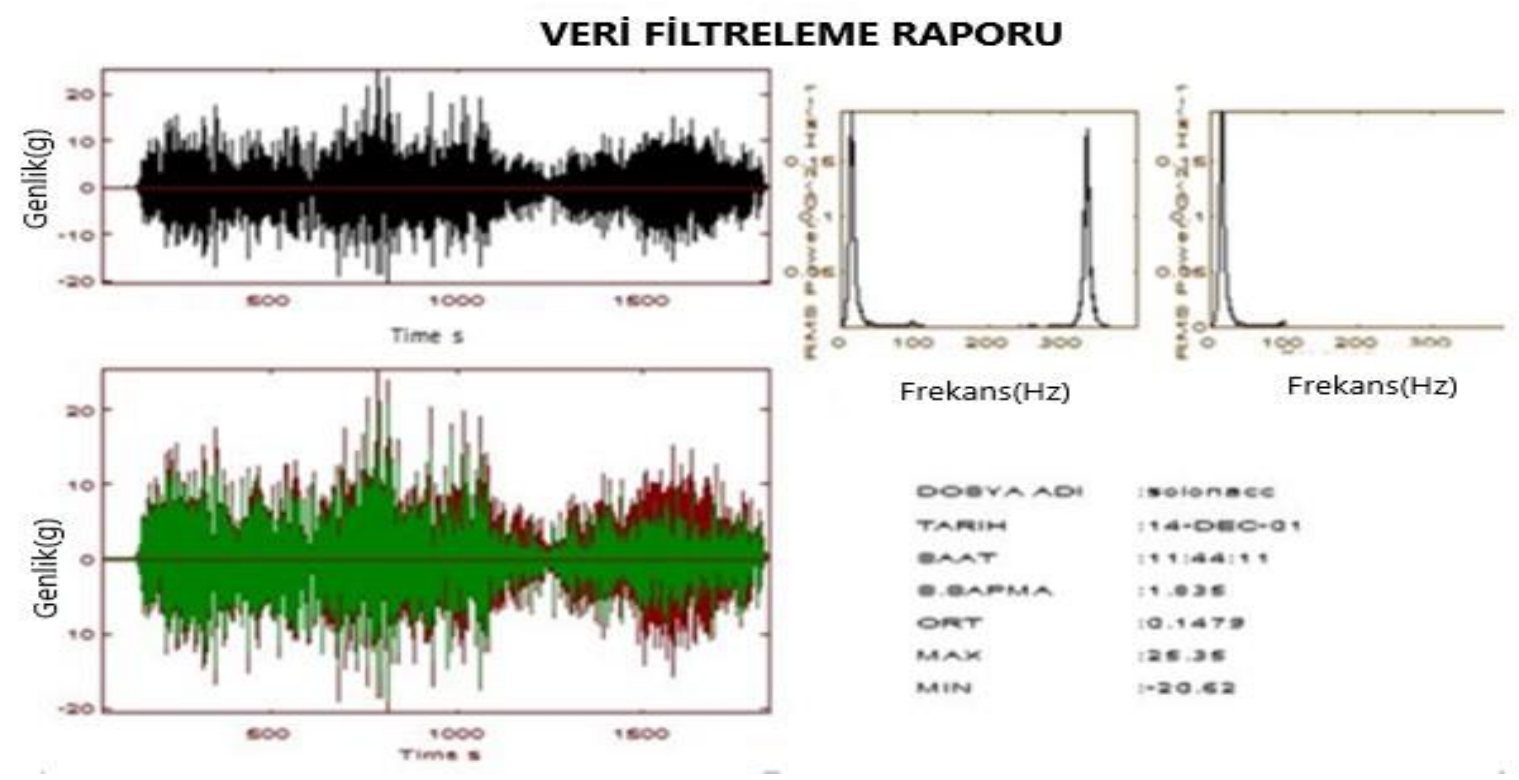

Şekil. 3. $100 \mathrm{~Hz}$ üzerindeki verilerin filitrelenmesi [15]

Aritmetik İşlemler: Araç yol testinin başlama zamanına kadar elde edilen veriler yorulma ömrünün hesaplanmasında yararlı olmadığından orjinal sinyallerden çıkarılmıştır [21].

Yol Uyarma Sinyallerinin İstatistiksel Sayımı: Zamana göre değişen yol sinyalleri rastgele ve devamlı olarak oluşur. Zamana bağlı sinyaller karşılaştırma için zamandan bağımsız olarak eşdeğer bir değere dönüştürülmelidir. Bu dönüşümün sağlanması için istatistiksel sayım metodları uygulanmıştır $[22,23]$. Stres gören parçalara ortalama gerilmeyi de hesaba katan 3-boyutlu yağmur akma istatiksel sayma metodu uygulanırken stres görmeyen parçalar için ise 2-boyutlu seviye -sayma metodu yapılmıştır [21, 22].

Hedef MP Oluşturma: Her bir yol verisi mesafe ve zaman açısından farklı oldugundan dolayı bu sinyallerin yorulma etkilerini mukayese edebilmek amaciyla her bir veri 1000 km'lik sinyale dönüştürülmüsşür. $1000 \mathrm{~km}$ verilerin sinyallerinin karşılaş̧tırılmasından sonra, sinyaller MP değerini oluşturmak için çeşitli yol tiplerine (şehir, şehirlerarası, dă ve otoyol) göre sınıflandırılarak ekstrapolasyon yapılmıştır [14, 15, 16]. Sınıflandırılmış $200.000 \mathrm{~km}$ MP verileri, anket sonuçlarından elde edilen Türk müşteri kullanım yüzdesi ile çarpılıplarak yol sınıflarının tümünü içeren her bir fiziksel büyüklük için bir MP oluşturulmuştur. Şekil 4, MP tahrik mili burulma verilerine ait 3B histogramını göstermektedir. 


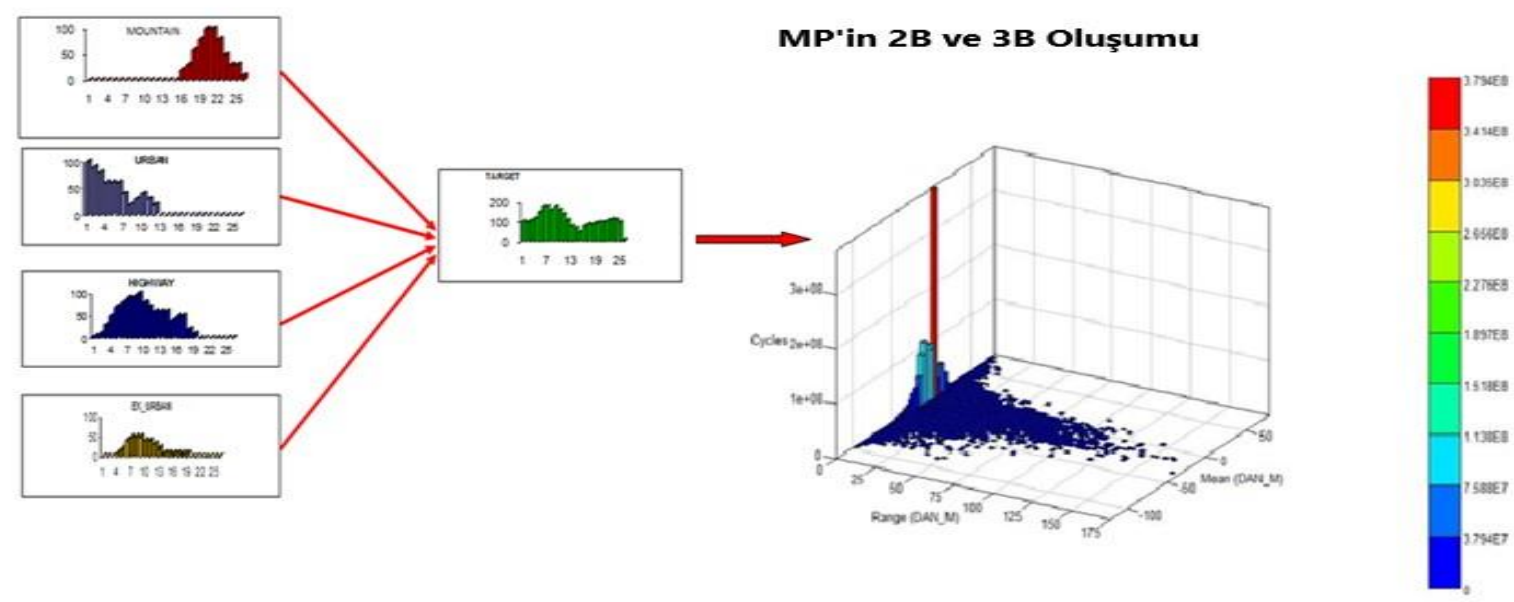

Şekil 4. Tahrik şaftı MP (200 $000 \mathrm{~km})$ Rain-flow 3D diyagramı [12]

MP'nin simülasyonu: Türk MP her bir sensör için oluşturulduktan sonra, aynı test aracıyla Bursa'daki otomobil fabrikasının civarında yorulma etkinliği ağır olan yollardan çeşitli sürüş koşullarında ve manevralarda test ölçümleri yapılarak kayıt edilmiştir. Daha sonraki adımda toplanan yol sinyalleri 1000 $\mathrm{km}$ ye normalize edilerek birbirleri arasında karşılaştırmalar yapılmıştır. Yorulma etkileri ağır olan parkurlar seçilmiştir ve $30.000 \mathrm{~km}$ ye ekstrapole edilmiştir. Bursa civarında toplanan veriler yol kullanım yüzdeleri ile çarpılarak $200.000 \mathrm{~km}$ MP yorulma etkisine tekabül eden $30.000 \mathrm{~km}$ 'lik HTP simulasyon verisi ağırlıklı ortalama metodu kullanılarak her bir sensör için oluşturulmuştur [14,15,16].

\section{DENEYSEL VERILEN AĞIRLIKLI ORTALAMA METODUNA GÖRE BENZEŞIMINININ KURULMASI (ESTABLISHMENT OF SIMILARITY OF EXPERIMENTAL DATA ACCORDING TO A WEIGHTING AVERAGE METHOD)}

\subsection{Ağırlıklı Ortalama Metodunun Tanımı}

$\mathrm{Bu}$ metod büyük veri demetlerinin çok sayıda tekrarı olan ancak sonlu bir sayıda seçilen veriler için kullanılır. Ağırlıklı ortalama yöntemi kavramı matematikten gelmektedir ve ortalama, çeşitli nicelikleri birlikte ekleyerek elde edilen sonuç olarak tanımlanabilir. Daha sonra bu toplam sayısının nicelik sayısına bölünmesiyle elde edilebilmektedir [16,24]. Bu çalışmada, her bir sensörden elde edilen verileri, 2boyutlu seviye sayma ve 3-boyutlu rainflow matrisleri ile oluşturulmuştur [16,21,22]. Bu matris değerleri her bir veri için ayrı ayrı bir bilgisayar yazılımına yerleştirilmiş ve daha sonra her bir sensöre ait veriler, her güzergahın indeksini hesaplamak ve aynı zamanda her bir değerin grafiklerinin çizilmesi için, Denklem 2, 3 ve 4 kullanılarak çevrimler ve aralıklar hesaplanmıştır [16].

$$
\begin{aligned}
& T C=\sum_{i=1}^{n} N_{i}=N_{1}+N_{2}+N_{3}+\cdots+N_{n} \\
& C P K=\frac{T C}{T K} \\
& M I=\frac{\sum_{i=1}^{n} a_{i} \cdot N_{i}}{T C}
\end{aligned}
$$

Burada;

$T C=$ Toplam çevrim

$\mathrm{CPK}=\mathrm{Km}$ deki çevrim

$M I=$ Ortalam Index

$a_{i} \quad=$ Fiziksel büyüklüğün aralığ1

$N_{i}=a_{i}$ aralığındaki çevrim adedi 


\subsection{MP ve HTP Arasında Yorulma Yollarının Hesaplanması ve Oluşturulması}

Bir yol benzetimi (simulasyonu) için araçtan mutlaka alınması gereken önemli parametreler;

$>$ araç süspansiyonunun dikey kuvvetlerin karakteristiği- aracın să̆ arkada ki gerinim ölçer donatılmış bir yaprak yay,

$>$ aracın süspansiyonuna yatay kuvvetlerin karakteristiği- aracın sağ önünde gerinim ölçer donatılmış direksiyon rod kolu,

$>$ aracın burulma karakteristiği- aracın sol önünde gerinim ölçer donatılmış tahrik mili,

$>$ araç gövdesine boylamasına kuvvetlerin karakteristiği- iki yönlü bir ivme ölçer ile

$>$ araç gövdesine yanal kuvvetin karakteristiği-iki yönlü bir ivme ölçer ile

> vites değişim oranı karakteristiği-araç km sensörü ve motor devri sensörleri kullanılarak,

$>$ frenleme karakteristiği- fren basınç transdüsörü fren hidrolik hattında belirlenerek veriler kayıt edilmiştir[15,16].

Ortalama ağırlıklı indeks metoduna göre, iki yolun her ne kadar birbirini yorulma açısından simule ettiği eğrilerin birbirlerini yakınsamasının yanında her bir yolun aritmetik ortalama indeks değerlerinin karşılaştırılması ile tespit edilir [16].

\section{SONUÇ (CONCLUSION)}

Bu çalışmada, Türkiye'de üretilen bir HTA'ın için sırasıyla Tablo 1 ve Tablo 2 de gösterildiği gibi Türk müşterisi araç kullanım oranları ile Türk müşterilerinin HTA kullanım amacı belirlenmiştir. Tablo 1, Türk müşterilerin binek HTA kullanımını göstermektedir.

Tablo 1. Türk müşsterisi HTA araç kullanımı [15]

\begin{tabular}{|l|l|}
\hline \multicolumn{1}{|c|}{ Yol tipi } & \multicolumn{1}{|c|}{ Yüzde } \\
\hline Şehir içi & $\% 50$ \\
\hline Şehirleraras1 & $\% 24$ \\
\hline Otoyol & $\% 20$ \\
\hline Dağ/tepe & $\% 6$ \\
\hline
\end{tabular}

Türk müşterisi binek HTA araç kullanım amacı ise Tablo 2 de sunulmuştur.

Tablo 2. Türk müşterisi HTA araç kullanım amacı[12]

\begin{tabular}{|l|l|}
\hline \multicolumn{1}{|c|}{ Kullanım amacı } & \\
\hline Ev-iş-ev & $\% 29$ \\
\hline İşten -işe & $\% 55$ \\
\hline Alışveriş ve dinlenme & $\% 4.7$ \\
\hline Haftasonu & $\% 5,4$ \\
\hline Tatil & $\% 5,5$ \\
\hline
\end{tabular}

Tablo 1'deki veriler, bir Avrupa ülkesi HTA araç kullanım oranları mukayese edildiğinde Şehir içi sürüş oranının Avrupa ülkesindeki HTA tipik bir kullanıcından iki katı olduğu tespit edilmiştir [15,16]. Türk müşterisi için HTA kullanımının birinci amacının İşten -İşe olduğu tespit edilmiştir [15]. 
MP ve HTP benzeșim eğrileri rainflow ve seviye sayma metodlarınıa göre eğrilerinin benzeșimleri ile bu verilerin indeks değerleri hesaplanarak sırasıyla ardı ardına Şekil 5' ten Şekil 12' ye kadar verilmiştir.

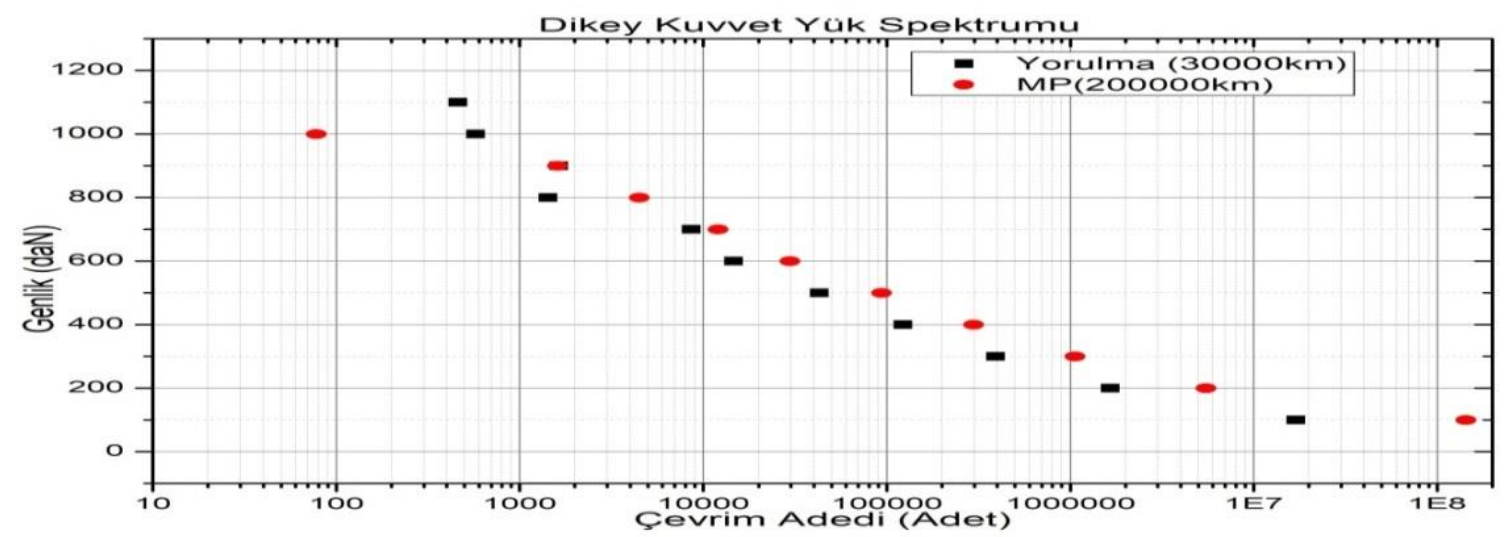

Şekil 5. MP ve HTP güzergahları arasında yaprak yay dikey yük spekturmu karşılaştırması

Şekil 5'te MP ve HTP yollarındaki araca ait dikey yük verilerinin karşılaştırılması sunulmuştur. Grafikten de görüleceği üzere, 900-1000 daN arasındaki dikey yükler açısından MP ve HTP arasındaki farklar, HTP içinde kullanılan birkaç bozuk yol verilerinden kaynaklanmaktadır. Dolayısıyla Türkiye'de toplanan verileri oluşturan MP değerleri büyük yükler açısından HTP verilerine ulaşamamıştır. Oysa her iki yol için 300 ile 900 daN dikey yük değerleri birbirine oldukça yakınsaktır.

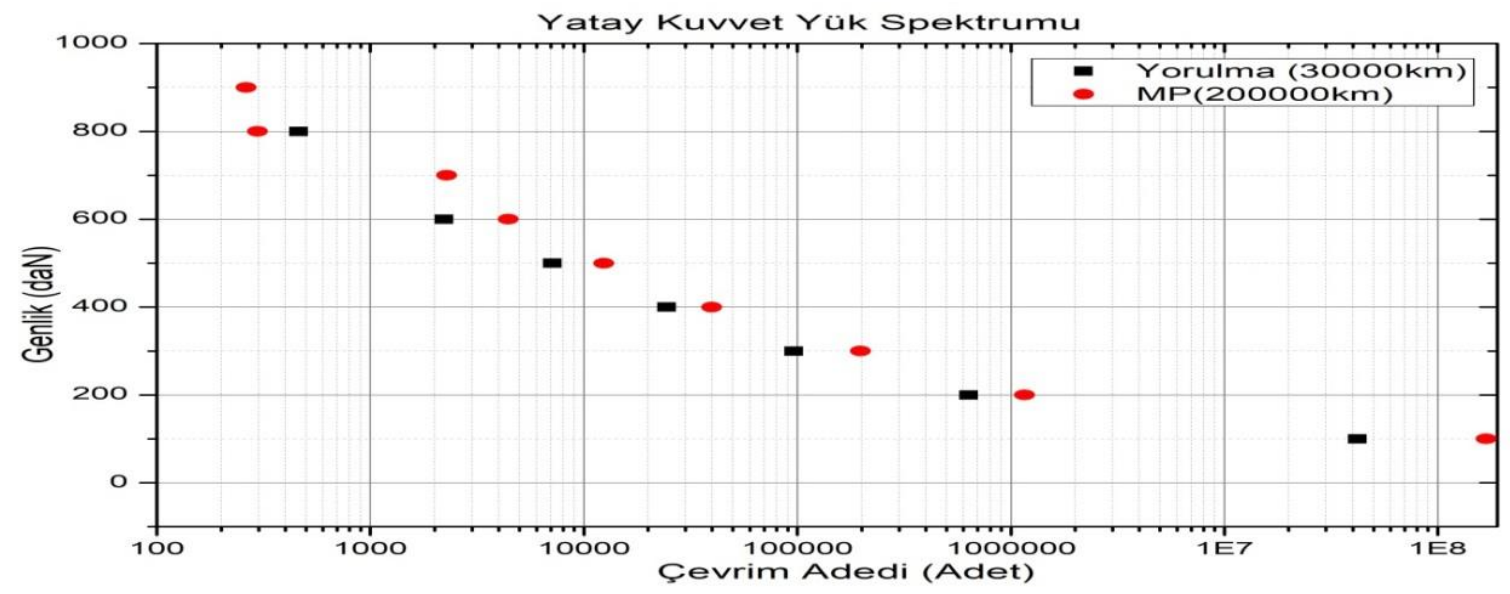

ŞekiL 6. MP ve HTP güzergahları arasında direksiyon rod kolu yatay yük karşılaştırması

Şekil 6'da, MP ve HTP güzergahları arasında virajlama ve sollama nedeniyle oluşan tekerlek yanal yüklerinin eğrileri verilmiștir. Her iki güzergâh da birbirine iyi bir şekilde yakınsamıștır. 


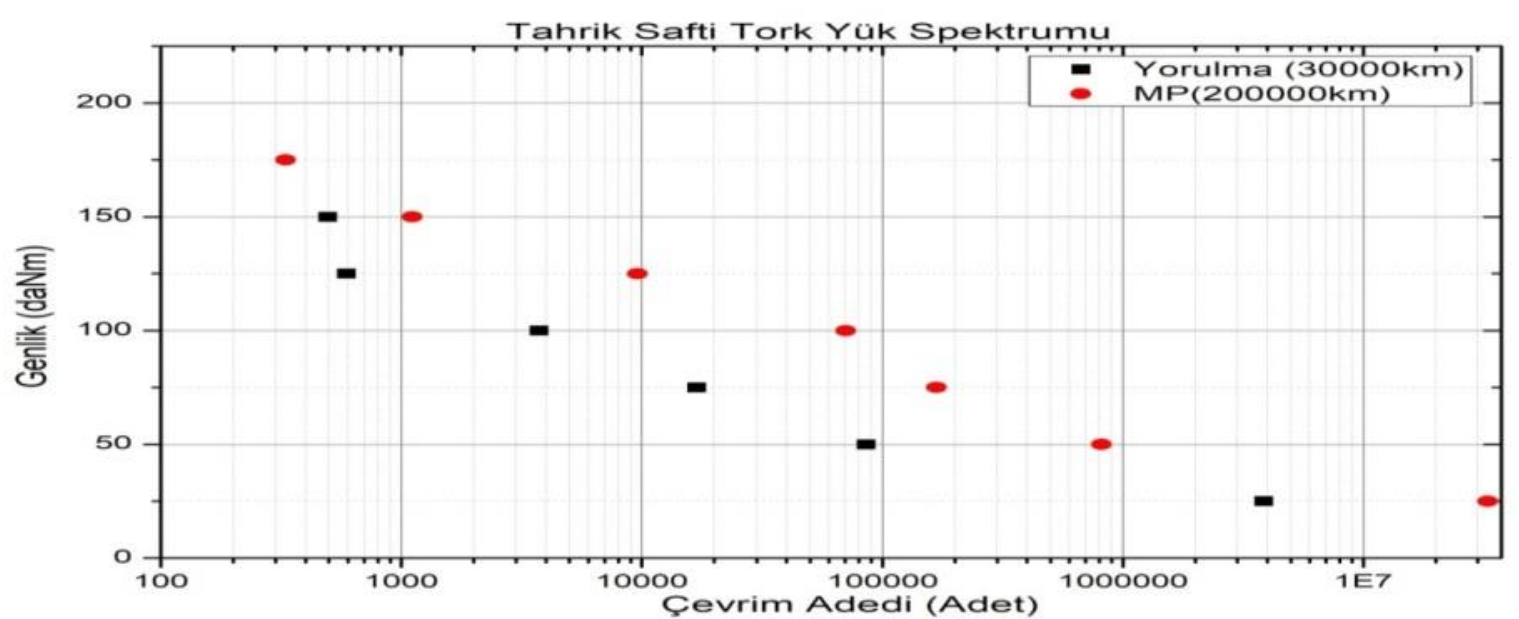

Şekil 7. MP ve HTP güzergahları arasında araç tahrik şaftının burulma yük dağılımı

Şekil 7'de MP ve HTP güzergahları arasında mukayeseli tahrik şaftı burulma eğrisi sunulmuştur. Grafiklerden görüldüğü gibi HTP eğrileri MP değrisine göre fark edeilir bir şekilde az yakınsamaktadır. Bunun sebebi MP'de kullanılan İstanbul şehiriçi araç kullanımınında trafik sıkışıklığı sebebi ile oluşan durma ve kalkmadan dolayı olduğu gözlenmektedir [12].

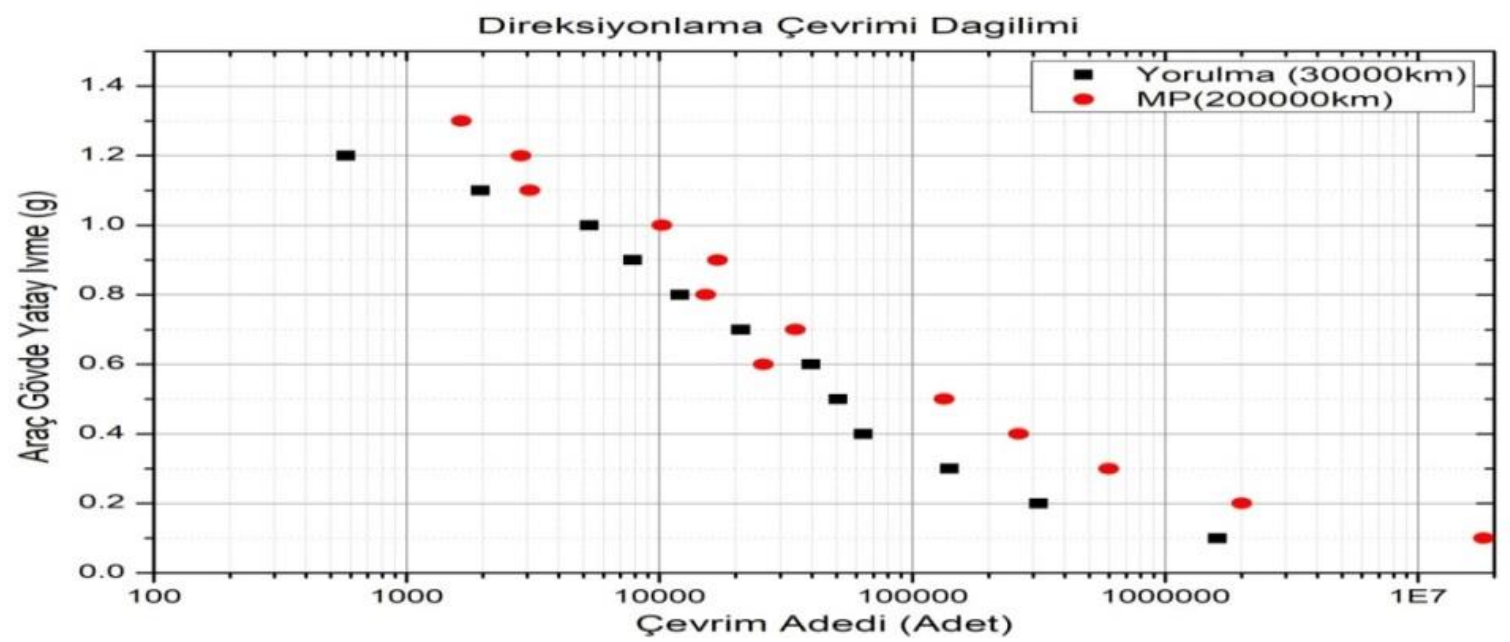

Şekil 8. MP ve HTP güzergahları arasında araç kasast yatay ivmelenme verileri yük spektrumları mukayesesi

Şekil 8'de MP ve HTP güzergahları arasında virajlama ve direksiyon manevralarından dolayı oluşan yanal ivme yük spektrumları verilmiştir. Grafiklerden görüldüğ̈ gibi, 0.7-1.3 g arasında birbirine oldukça yakınsamışken buna karşın $0.6 \mathrm{~g}$ civarında MP çevrim adedi HTP verilerinden az bir şekilde daha fazladır. 


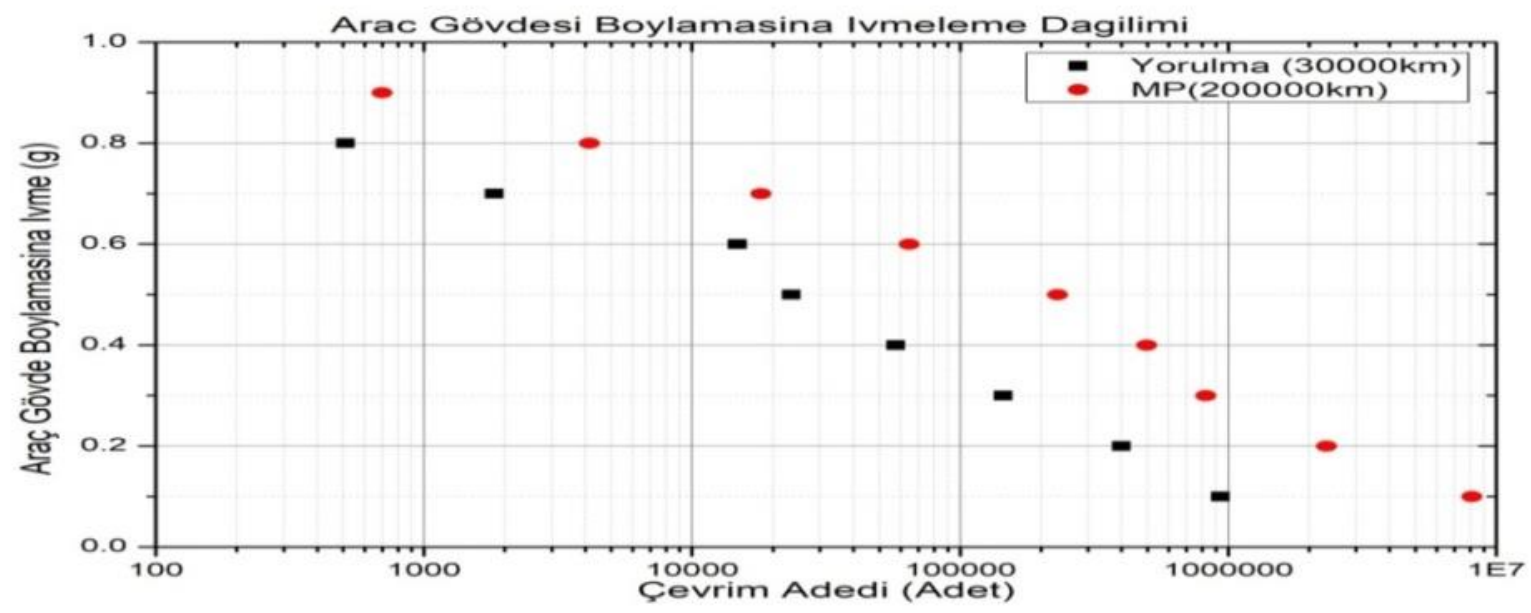

Şekil 9. MP ve HTP güzergahları arasında arac kasası boylamasına ivmeleme yük spekturumu mukayesesi.

Şekil 9'da MP ve HTP güzergahları arasında durma ve kalkmadan, frenlemeden ve yolların sinizoidal eğiminden dolayı araç kasasınında oluşan boylamasına ivmeleme yük spektrumu dağılımı verilmiştir.

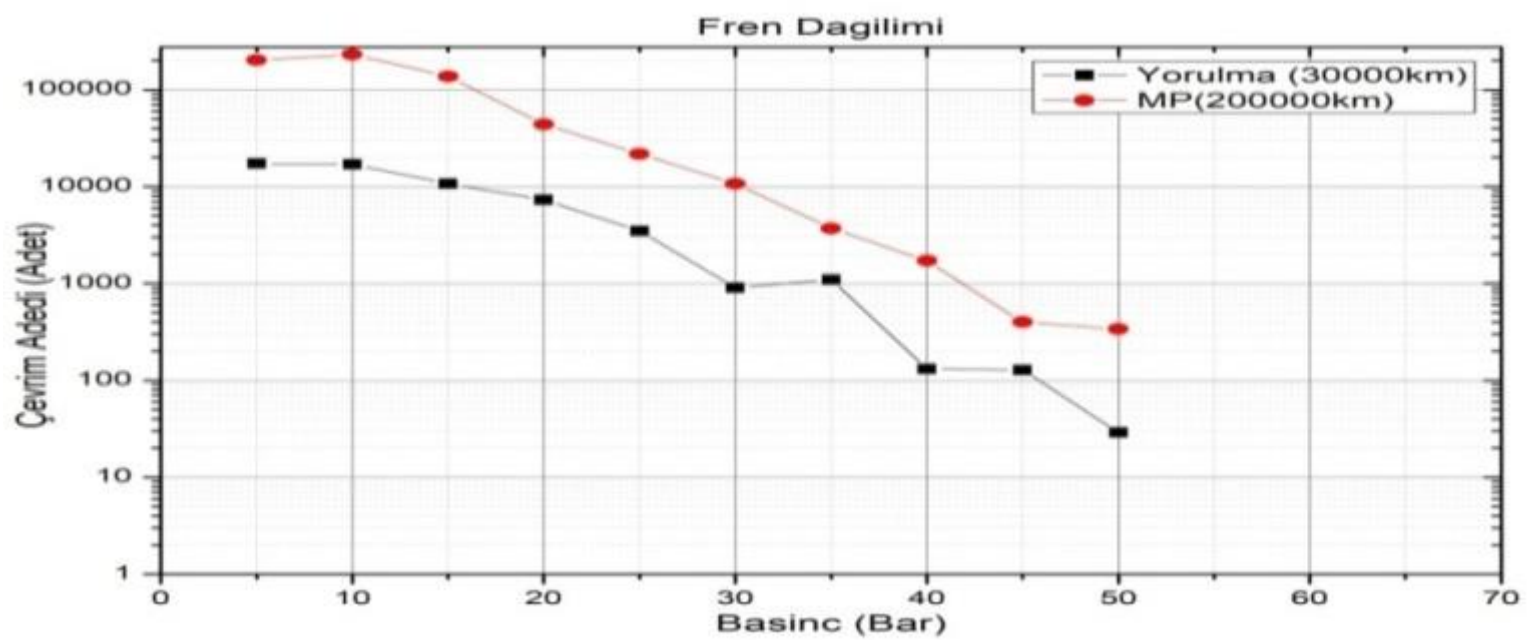

Şekil 10. MP ve HTP güzergahları arasında araç frenleme yük spekturumu mukayesesi.

Şekil 10 da MP ve HTP güzergahları arasında fren basıncı ve fren adetleri yük spekturumu dağılımı mukayeseli olarak verilmiştir. HTP güzergahındaki yük spekturumu verileri MP güzergahındaki fren adedi index değerine yeterince kadar yakınsamamıştır. Bunun nedeni MP güzergahında kullanılan şehir içi yolunda İstanbul şehir içi verilerinin HTP güzergahında kullanılan şehiriçi güzergahı verilerine göre çok aşırı bir şekilde dur ve kalk manevraları içermesinden dolayıdır. 


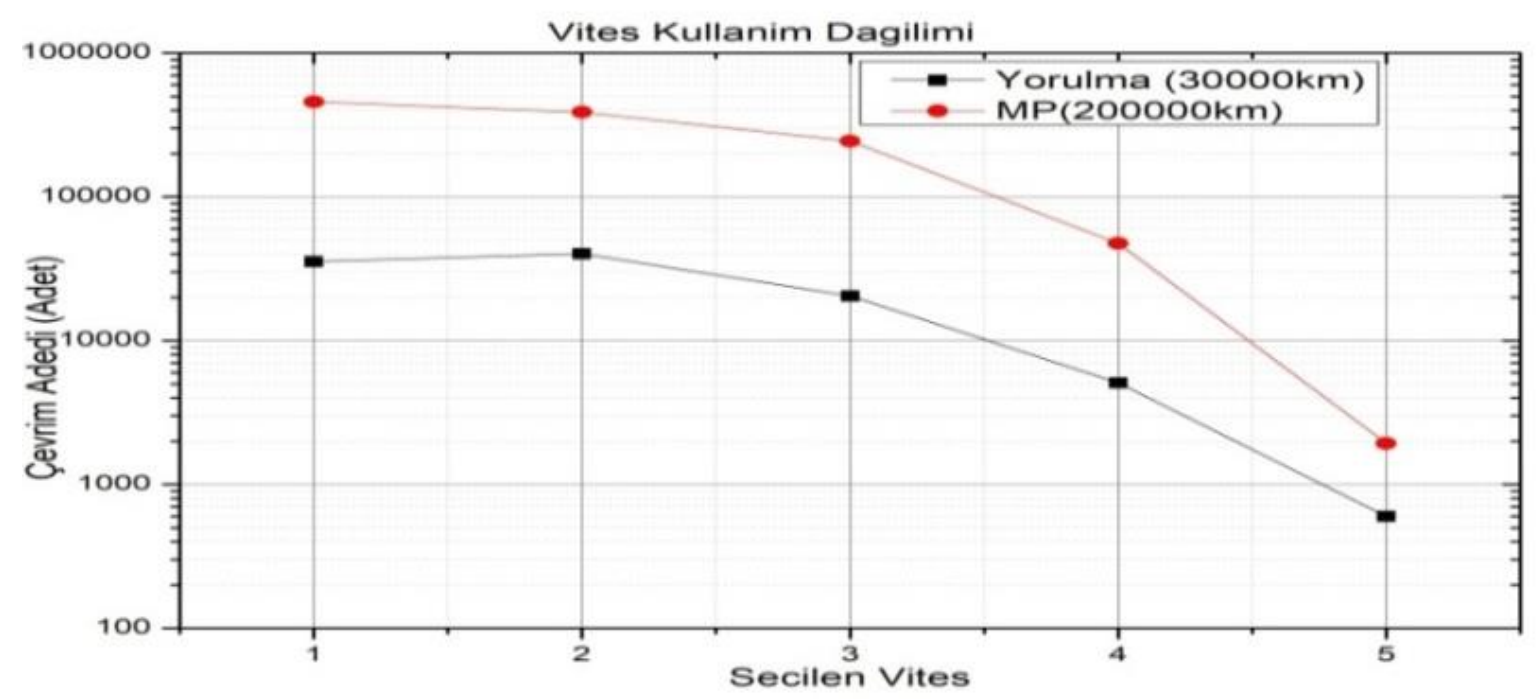

Şekil 11. MP ve HTP güzergahları arasında araç vites değişim oranlarının mukayeseli yük spekturumu dă̆ılımı

Şekil 11'de MP ve HTP güzergalarında araç vites değişim oranları yük spekturumu verilmiştir. Grafikten görüldüğü gibi HTP güzergahındaki indeks değeri MP güzergahındaki indeks değerinden daha ağırdır. Bu grafik çevrim adetleri açısından değerlendirildiğinde MP güzergahındaki yük miktarı özellikle 4. vites oranına kadar çok daha ağırdır. Bunun nedeni MP güzergahında kullanılan İstanbul şehir içi tarfiğinin çok miktarda dur ve kalk manevrası içermesindendir.

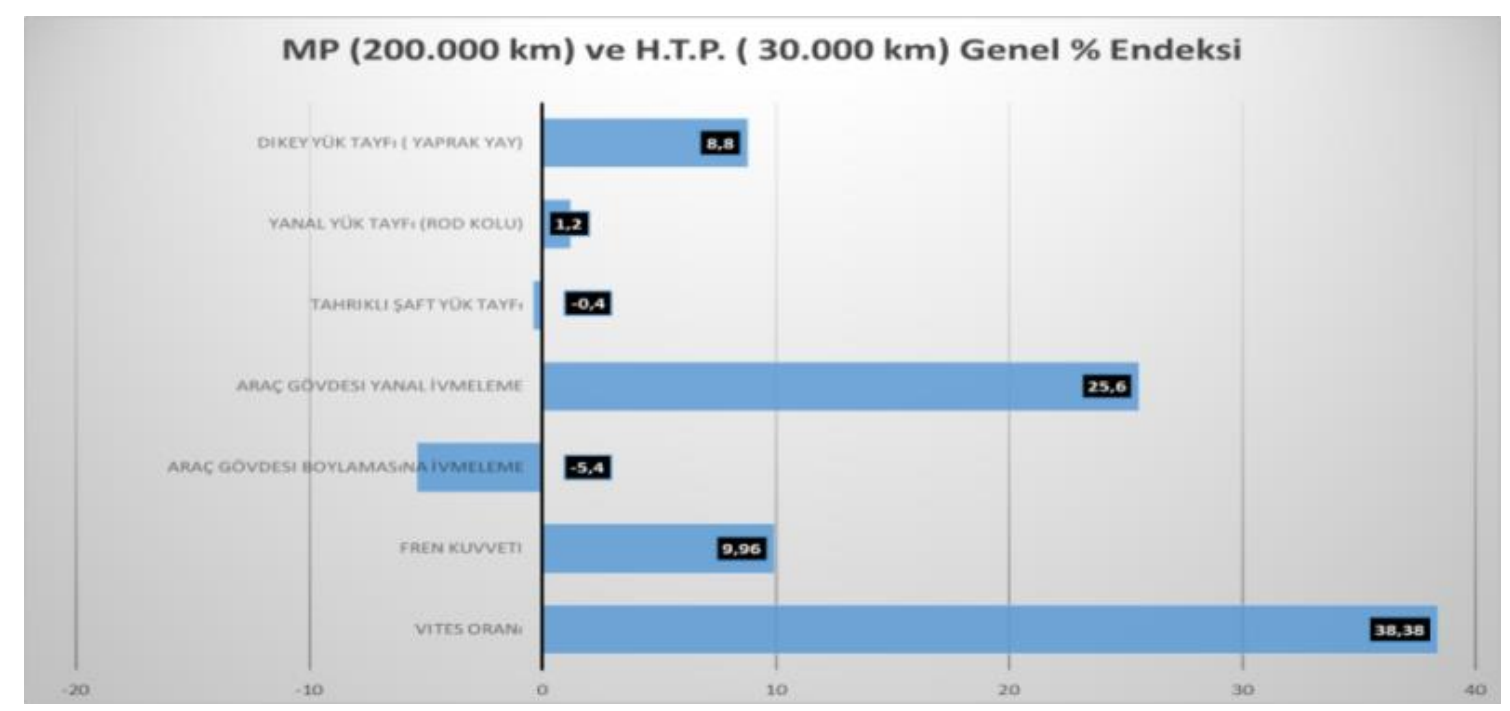

Şekil 12. MP ve HTP güzergahlarının genel indeks mukayesesi

Şekil 12, MP $200.000 \mathrm{~km}$ ve HTP $30.000 \mathrm{~km}$ genel yüzdesinin oranlamasını göstermektedir. $30.000 \mathrm{~km}$ HTP genel ortalama indeks değerinin MP $200.000 \mathrm{~km}$ genel ortalama \% indeks oranı olarak yaklaşı \% 24 daha ağır bir parkur olduğu tespit edilmiştir [16].

Sonuç olarak Türk sürücülere özgü bir HTA araç için MP karakteristik verisi geliştirilmiştir. Her bir sensor için matematiksel bir MP $(200.000 \mathrm{~km})$ ağırlıklı ortalama metoduna göre oluşturulmuştur. Yeni modellerin geliştirilmesinde kullanılacak olan dayanım testi için bir yorulma test parkuru üretici firma yakınlarında bir HTA için hesaplanarak tasarlanmıştır. 
Şekil 10' daki ve şekil 11' deki fren adedi ve vites değişim oranı farkını ilgili otomobil üretici firma ürün geliştirme sırasındaki yorulma testleri sırasında normal yol güzergahlarına ilave olarak fabrika içinde uygun bir alanda ilave manevralarla bu farkı gidermeleri sonuçunda eğriler tamamıyla birlerine yakınsamaları sağlanmış olacaktır.

$\mathrm{Bu}$ çalışmayla kritik yük kuvvet aralıkları saptanmış ve bundan sonraki ürün geliştirilmesinde kullanılmak üzere bir veri tabanı olarak arşivlenmiştir.

\section{KAYNAKLAR (REFERENCES)}

[1] A.T.M.J.M. Huizinga, M.A.A. Van Ostajen, G.L. Slingeland. A practical approach to virtual testing in automotive engineering, Journal of Engineering Design . 13 (2002) 33-47

[2] V. Grubisic . Criteria and methodology for lightweight design of vehicle components, FraunhoferInstitut fur Betriebsfestigkeit(LBF), Darmstadt, Germany (1986) DOI:10.4271/850367

[3] K.DreBler, M.Speckert, R.Müller,Ch.Wber. Customer loads correlation in truck engineering, Berichte des Fraunhofer ITWMNr. 151 (2009),F200812198 ISSN 1434-9973

[4] B. Dodson and H. Schwab Practitioner's guide to accelerated and reliability testing (2006);ISBN-10 0-7680-0690-2 ISBN-13978-0-7680-0690-2,

[5] V.Grubisic. Determination of load spectra for design and testing, International Journal of Vehicle Design . 15(1994) 8-26

[6] N. W. M. Bishop, F. Sherratt . Finite Element Based Fatigue Calculation, NAFEMS International Association for the Engineering Analysis Community. (2000) USA DOI:10.1111/j.14602695.1990.tb00604.x

[7] nCode International Inc.\&MSC Software Corporation : User manuel MSC Corporation ,Los Angles, USA,(1998)

[8] K.Ahlin, J. Granlund, F. LindströmComparing road profiles with vehicle percived roughness, International Journal of Vehciles Design. 36 (2004) 270-286

[9] E. S. Palma, F. A. C. Vidal. Fatigue damage analysis on body shell passenger vehicle,Journal of Materials Engineering and Performance. 11 (2002) 450-460 DOI:10.1361/105994902770343999

[10] B. Oelmann. Determination of load spectra for durability approval of car drive lines, Fatigue and Fracture of Engineering Materials and Structures 25 (2002) 1121-1125 DOI:10.1046/j.14602695.2002.00604.x

[11] A. S. Şener. Finite element based vehicle component fatigue life assessment according to a customer usage profile, Materials Testing. 56 (2014) 198-207, DOI:10.3139/120.110543

[12] A. S. Sener Fatigue life assessment of the driving shaft of a LCV by FEA using customer correlation data Materials Testing. 58:4 (2016) 325-332, DOI.10.3139/120.110861H.

[13] A. S. Şener.Determination of vehicle components fatigue life based on FEA method and experimental analysis, International Journal of Electronics, Mechanical and Mechatronics Engineering. 2 (2003) 133-45

[14] Case Study - Complate Customer Usage Profiling Example Raw Data Through Track Correlation to Accelerated Rig Drive in 4 Days, Iveco, Italy, nCode, UK, (1999).

[15] Ş.A.Şener Fatigue life determination of the leaf spring on the light commercial vehicle acccording to Turkish Mission Profile (in Turkish), Istanbul, Turkey. (2003) 
[16] V.Pizzari.Turkish Mission Profile Research Segment B Vehicle, Turkish Instructions Prot. No.11998", Arese, 04 February, Direction of Technical Development Vehicle Reliabilityand Terreni Laboratory Test Measurements, Study Report (in Italian)

[17] C.Marchesani, F.Parmigiani, M.Vianello Integrated method to define the mission profile of a passenger car, FIAT Auto SpA. (1979) 45-54 (in Italian)

[18] M.Fantacchiotti, M.VianelloGradual improvement of the vehcile reliability up to the target value, FIAT Auto SpA Design Engineering Department, 4th International Conference. 1994)1-5

[19] P. K. Paul, R. K. Dunga, A. Verma, A. V. Minakar, S. Raju.Techniques for accelerated design validation of tractor chassis, SAE Paper. 1(2001) 1-50 DOI:10.4271/2001-26-0050.

[20] F. D'Aprile, et al. Structural characterization of a vehicle on a rig test versus different road profiles: analysis of experimental results. ATA-TORINO-. 54:7/8 ( 2001) 251-261

[21] MSC. Software GmbH nSoft 5.2 User Manuel 1999

[22] ASTM Standard E 1049-85, Philadelphia, USA 1997

[23] N.Bishop et al .Analytical Fatigue Life Assessment of Vibration Induced Fatigue Damage . MSC World Users Conference, Universal City, CA. 1995.

[24] S.X.Xie, D. Liao and V.M. Chinchilli. Measurement Error reduction Using Weighted Average Method for Repeated Measurements from Heterogeneous Instrument Environmetrics 12(2001) 785790 (DOI:10.1002/env.511). 